\title{
Competitive adsorption of molybdate, chromate, sulfate, selenate, and selenite on $\gamma-\mathrm{Al}_{2} \mathrm{O}_{3}$
}

\author{
Chung-Hsin $\mathrm{Wu} *$, Shang-Lien Lo, Cheng-Fang Lin
}

Graduate Institute of Environmental Engineering, National Taiwan University, 71 Chou-Shan Road, Taipei 106, Taiwan, ROC

Received 8 September 1998; accepted 19 August 1999

\begin{abstract}
Competitive adsorption of molybdate, selenite, selenate, chromate, and sulfate onto $\gamma-\mathrm{Al}_{2} \mathrm{O}_{3}$ was investigated in the present study. Binary-solute systems of $\mathrm{MoO}_{4}^{2-} / \mathrm{SeO}_{3}^{2-}, \mathrm{CrO}_{4}^{2-} / \mathrm{SO}_{4}^{2-}$, and $\mathrm{CrO}_{4}^{2-} / \mathrm{SeO}_{4}^{2-}$ as well as single anion systems were evaluated for the relative influence on competitive adsorption on oxide surface. As would be expected, the adsorption density of each anion in the binary-solute systems decreases, as compared to the respective density in a single anion system. Furthermore, $\mathrm{MoO}_{4}^{2-}$ inhibits $\mathrm{SeO}_{3}^{2-}$ adsorption in acidic condition and that $\mathrm{SO}_{4}^{2-}$ or $\mathrm{SeO}_{4}^{2-}$ depresses $\mathrm{CrO}_{4}^{2-}$. The order of the relative retainment of anions on oxide surface is molybdate $>$ selenite $>$ selenate $\sim$ sulfate $>$ chromate, which corresponds to the magnitude of the overall proton coefficient of the corresponding anions. (C) 2000 Elsevier Science B.V. All rights reserved.
\end{abstract}

Keywords: Competitive adsorption; Molybdate; Chromate; Sulfate; Selenate; Selenite; TLM

\section{Introduction}

Mobility of anions in aquatic environment is generally regulated by adsorption at the solid/water interface as well as competition for surface binding sites among various anion species. In the past decades, several studies have been devoted for elucidating anion interactions with minerals and $\mathrm{Fe} / \mathrm{Al}$ oxides [1-8]. In those studies, molybdate, chromate, selenate, selenite, arsenate, arsenite, phosphate and sulfate are investigated because they are essential trace nutrients as well as toxic substances to plants and aquatic life. Anion ad-

\footnotetext{
* Corresponding author. Tel.: + 886-2-2392-7653; fax: + 886-2-2362-7427.
}

sorption at the oxide/water interfaces is commonly interpreted by the surface complexation mechanism in which anionic solute is binding to the surface reacting site to form either innersphere or ion-pair complex. Based on the effect of solution ionic strength and simulation by triplelayer modeling (TLM), adsorption of selenite, chromate, arsenate, and molybdate are regarded as specific coordination with surface hydroxyl groups $[5,8,9]$. Sorption of sulfate, however, has been typically recognized to form an outer-sphere complex $[4,10]$. With the use of extended X-ray absorption fine structure spectroscopy, surface configuration of the anion inner-sphere complex is further evident $[11,12]$. 
Anion partitioning onto oxide surfaces is also greatly affected by the competitive adsorption of anionic cosolutes in the aqueous systems [2,13,14]. Anions with comparable adsorptive affinities for oxide reacting sites can exhibit a pronounced effect on competitive adsorption over a wide environmental condition and relative concentration [13]. For example, Roy et al. [13] indicated that the adsorption of arsenate and molybdate was significantly reduced by the competitive adsorption of phosphate. Nevertheless, adsorption of strongly binding anions can only be depressed if the weakly binding anions are present in a large excess amount and under low $\mathrm{pH}$ conditions [14]. Mesuere and Fish [6] showed that the sorption of chromate onto $\alpha-\mathrm{FeOOH}$ in acidic environments was diminished by the competitive adsorption of organic oxalate. Sulfate has been shown to decrease the adsorption of $\mathrm{As}(\mathrm{III})$ and $\mathrm{As}(\mathrm{V})$ in acidic systems [7,15]. Dynes and Huang [16] also indicated that the competitiveness of the organic acids with selenite for sorption sites increased with increasing organic acid concentration.

In most of the previous studies, influence of competitive adsorption on anion partitioning has been addressed in binary-solute systems containing strongly binding anion with organic compound or sulfate $[16,17]$. A systematic investigation on the relative competition for sorption onto oxides among various anions with different binding affinity is rather limited. In practical situations, multi-component mixture competition might increase the complexity of anion interaction at the water/oxide interfaces. Such complex systems frequently occur, and the magnitude of these competitive interactions needs to be clarified in order to better predict contaminant behavior and to identify anions that are more likely to be affected in their transport in the presence of other anions. Consequently, this study focuses on the competitive adsorption of molybdate, chromate, sulfate, selenate, and selenite onto $\gamma-\mathrm{Al}_{2} \mathrm{O}_{3}$. The findings are of fundamental significance in better understanding the influence of competitive adsorption on the fate of anions in the environment.

\section{Materials and methods}

\subsection{Materials}

All solutions were prepared with deionized water (Milli-Q) and reagent-grade chemicals. Stock anion solutions $\left(10^{-2} \mathrm{M}\right)$ were prepared with $\mathrm{Na}_{2} \mathrm{MoO}_{4}, \quad \mathrm{Na}_{2} \mathrm{CrO}_{4}, \quad \mathrm{Na}_{2} \mathrm{SO}_{4}, \quad \mathrm{Na}_{2} \mathrm{SeO}_{4}, \quad$ or $\mathrm{Na}_{2} \mathrm{SeO}_{3}$. The background electrolyte $\mathrm{NaNO}_{3}$ concentrations were adjusted to $0.01,0.05$, and $0.1 \mathrm{M}$. The adsorbent $\gamma-\mathrm{Al}_{2} \mathrm{O}_{3}$ obtained from Aerosil Co. (Japan) was purified by electrodialysis $(1200 \mathrm{~V}, 3 \mathrm{~mA})$ before use in the sorption experiments. The impure substances which could easily affect adsorption results were removed by the purification procedures.

\subsection{Sorption experiments}

In batch equilibrium adsorption experiments, anions $\left(5 \times 10^{-3} \mathrm{M}\right)$ were equilibrated with $\gamma$ $\mathrm{Al}_{2} \mathrm{O}_{3}$ suspension $(30 \mathrm{~g} / 1)$ in the presence of 0.01 , 0.05 , or $0.1 \mathrm{M} \mathrm{NaNO}_{3}$. A small amount of $\mathrm{HNO}_{3}$ or $\mathrm{NaOH}$ was added to cover the $\mathrm{pH}$ range 4.5-9 for $\mathrm{MoO}_{4}^{2-}, \mathrm{pH} 2-10$ for $\mathrm{CrO}_{4}^{2-}$ and $\mathrm{SO}_{4}^{2-}, \mathrm{pH}$ 2-9 for $\mathrm{SeO}_{4}^{2-}$, and $\mathrm{pH} 5-10$ for $\mathrm{SeO}_{3}^{2-}$. After the desired $\mathrm{pH}$ was reached, $10 \mathrm{ml}$ of the suspension was removed to a 15-ml polypropylene tube. All experiments were performed in a tightly capped $15-\mathrm{ml}$ polypropylene tube under $\mathrm{N}_{2}$ atmosphere at $25 \pm 0.1^{\circ} \mathrm{C}$ for $24 \mathrm{~h}$. At the end of the equilibrium period, the $\mathrm{pH}$ of each suspension was determined. The suspensions were centrifuged at $9500 \mathrm{rpm}$ for $10 \mathrm{~min}$, and the supernatant was then filtered through $0.2 \mu \mathrm{m}$ filter paper (Gelman Sciences) for later analyses of anion concentration. In competitive adsorption experiments, same concentrations of adsorbate and adsorbent were used. Three binary-solute systems as $\mathrm{pH} 4.5-9$ for $\mathrm{MoO}_{4}^{2-}+\mathrm{SeO}_{3}^{2-}$, pH $2-10$ for $\mathrm{SO}_{4}^{2-}+\mathrm{CrO}_{4}^{2-}$ and $\mathrm{SeO}_{4}^{2-}+\mathrm{CrO}_{4}^{2-}$ were designated for understanding the relative binding strength between anions.

All anion concentrations were determined by ion chromatography (Dionex 2000i SP). The specific surface area of $\gamma-\mathrm{A}_{2} \mathrm{O}_{3}$ was calculated to be $100 \mathrm{~m}^{2} / \mathrm{g}$ based on the BET measurements. 


\subsection{Modeling of adsorption data}

The TLM developed by Davis and Leckie [18] and subsequently modified by Hayes and Leckie [19] was used for simulating the equilibrium partitioning of anion species and background electrolyte ions at the $\gamma-\mathrm{Al}_{2} \mathrm{O}_{3} /$ water interface. As described previously, model analogous of two different types of surface complexes can be incorporated to TLM, either as inner-sphere or outer-sphere ion-pair complexes. The former corresponds to ions placed in the $o$-plane, the latter to ions placed in the $\beta$-plane. The TLM parameters and intrinsic acidity surface hydrolysis constants $\left(K_{\mathrm{a} 1}^{\mathrm{int}}\right.$ and $\left.K_{\mathrm{a} 2}^{\mathrm{int}}\right)$ and binding constants $\left(\mathrm{K}_{\mathrm{Na}}^{\mathrm{int}}\right.$ and $\left.K_{\mathrm{NO}_{3}^{-}}^{\text {int }}\right)$ of the background electrolyte $\left(\mathrm{NaNO}_{3}\right)$ with the surface are described in Table 1. Potentiometric titration experiments on $10 \mathrm{~g} / 1$ $\gamma-\mathrm{Al}_{2} \mathrm{O}_{3}$ suspensions with three different background electrolyte concentrations $(0.1,0.01$ and $0.001 \mathrm{~N})$ to calculate $K_{\mathrm{a} 1}^{\mathrm{int}}$ and $K_{\mathrm{a} 2}^{\mathrm{int}}$ and $\mathrm{K}_{\mathrm{Na}^{+}}^{\mathrm{int}}$ and $K_{\mathrm{NO}_{3}^{-}}^{\text {int }}$ follow the method of Davis et al. [22]. The acidity constants were determined by extrapolating the titration data at lowest $\mathrm{NaNO}_{3}$ concentration to zero fractional ionization. Similarly, the electrolyte binding constants were estimated by extrapolating the higher $\mathrm{NaNO}_{3}$ concentrations results to zero fractional ionization. The $\log K_{\mathrm{a} 1}^{\mathrm{int}}$, $\log K_{\mathrm{a} 2}^{\mathrm{int}}, \log K_{\mathrm{Na}^{+}}^{\mathrm{int}}$ and $\log K_{\mathrm{NO}^{-}}^{\mathrm{int}}$ determined in this work were $-6.9,-9.7,-8.3$ and 6.9 , respectively. For comparison, the $\log K_{\mathrm{a} 1}^{\mathrm{int}}$ and $\log K_{\mathrm{a} 2}^{\mathrm{int}}$ values reported by Hohl and Stumm [23] were -7.2 and -9.5 . The $\log K_{\mathrm{Na}^{+}}^{\mathrm{int}}$ and $\log K_{\mathrm{NO}_{3}^{-}}^{\mathrm{int}}$ values reported by Zhang and Sparks [4] and Hayes and Leckie [19] were - 9.1 and 8.7.

Table 1

TLM parameters for $\gamma-\mathrm{Al}_{2} \mathrm{O}_{3}$ used in this study

\begin{tabular}{ll}
\hline Specific surface area $\left(\mathrm{m}^{2} / \mathrm{g}\right)$ & $100(\mathrm{BET}$ measurement $)$ \\
Site density $\left(\right.$ sites $\left./ \mathrm{nm}^{2}\right)$ & $8[20]$ \\
Outer-layer capacitance & $20[21]$ \\
$\quad\left(\mathrm{C}_{2}, \mu \mathrm{F} / \mathrm{cm}^{2}\right)$ & $80[21]$ \\
Inner-layer capacitance & \\
$\left(\mathrm{C}_{1}, \mu \mathrm{F} / \mathrm{cm}^{2}\right)$ & $-6.9,-9.7$ (acid $/$ base \\
$\log K_{\mathrm{a} 1}^{\text {int }}, \log K_{\mathrm{a} 2}^{\text {int }}$ & titration $)$ \\
$\log K_{\mathrm{Na}+}^{\text {int }}, \log K_{\mathrm{NO}_{\overline{3}}}^{\text {int }}$ & $-8.3,6.9($ acid $/$ base \\
& titration $)$
\end{tabular}

Table 2

Aqueous proton dissociated reaction constants used in this study

\begin{tabular}{lll}
\hline Species & Reactions & Constants \\
\hline $\mathrm{H}_{2} \mathrm{MoO}_{4}$ & $\mathrm{HMoO}_{4}^{-}=\mathrm{H}^{+}+\mathrm{MoO}_{4}^{2-}$ & $\mathrm{p} K_{2}=4.21$ \\
$\mathrm{H}_{2} \mathrm{CrO}_{4}$ & $\mathrm{HCrO}_{4}^{-}=\mathrm{H}^{+}+\mathrm{CrO}_{4}^{2-}$ & $\mathrm{p} K_{2}=6.49$ \\
$\mathrm{H}_{2} \mathrm{SO}_{4}$ & $\mathrm{HSO}_{4}^{-}=\mathrm{H}^{+}+\mathrm{SO}_{4}^{2-}$ & $\mathrm{p} K_{2}=1.99$ \\
$\mathrm{H}_{2} \mathrm{SeO}_{4}$ & $\mathrm{HSeO}_{4}^{-}=\mathrm{H}^{+}+\mathrm{SeO}_{4}^{2-}$ & $\mathrm{p} K_{2}=1.92$ \\
$\mathrm{H}_{2} \mathrm{SeO}_{3}$ & $\mathrm{H}_{2} \mathrm{SeO}_{3}=\mathrm{H}^{+}+\mathrm{HSeO}_{3}^{-}$ & $\mathrm{p} K_{1}=2.62$ \\
& $\mathrm{HSeO}_{3}^{-}=\mathrm{H}^{+}+\mathrm{SeO}_{3}^{2-}$ & $\mathrm{p} K_{2}=8.32$ \\
\hline
\end{tabular}

${ }^{a}$ From Perrin [24].

Aqueous dissociated reaction constants are summarized in Table 2.

Ion-pair formation and surface coordination may occur at oxide/water interface. The reactions and equilibrium expressions in the TLM are summarized in Table 3, in which $R$ is the gas constant; $T$ is the absolute temperature; $F$ is the Faraday constant; $\psi_{\mathrm{o}}$ is the surface potential on $o$-plane; and $\psi_{\beta}$ is the surface potential on the $\beta$-plane. Eqs. (1) and (2) in Table 3 describe protonation of reacting surface sites, and Eqs. (3) and (4) show the formation of complexes between the background electrolyte ions and the surface. Ion-pairs are formed at the $o$-plane (Eqs. (5) and (6)), where the adsorption is nonspecific and the reaction product is an outer-sphere surface complex if anions react similarly to a background electrolyte with SOH. If adsorption of anions is visualized as a chemically specific reaction, the reaction can then be expressed as an inner-sphere surface coordination process (Eqs. (7) and (8)).

The parameters and equations in Tables 1-3 were used in the model analysis to determine the best-fit intrinsic equilibrium constants for the anion $/ \gamma-\mathrm{Al}_{2} \mathrm{O}_{3}$ reactions.

\subsection{Kurbatov plots for overall proton coefficient}

Differences in anion adsorption on $\gamma-\mathrm{Al}_{2} \mathrm{O}_{3}$ can be examined from the slope of the Kurbatov plots for the adsorption data [3]. The anion adsorption reactions may be generalized by the following equation, in which the Kurbatov plot is based:

$$
\mathrm{SOH}+n \mathrm{H}^{+}+\mathrm{L}^{2-}=\mathrm{SOH}_{n+1} \mathrm{~L}^{(n-2)}
$$


$K_{\mathrm{e}}=\frac{\left[\mathrm{SOH}_{n+1} \mathrm{~L}^{(n-2)}\right]}{[\mathrm{SOH}]\left[\mathrm{H}^{+}\right]^{n}\left[\mathrm{~L}^{2-}\right]}$

where $K_{\mathrm{e}}$ is an apparent equilibrium constant, $\mathrm{SOH}$ is proton-specific surface sites, and

Table 3

Surface complexation reactions and equilibrium expressions for anion $/ \gamma-\mathrm{Al}_{2} \mathrm{O}_{3}$ systems ${ }^{\mathrm{a}}$

\begin{tabular}{ll}
\hline Reactions & Intrinsic equilibrium expressions \\
$\begin{array}{l}\mathrm{SOH}_{2}^{+}=\mathrm{SOH} \\
+\mathrm{H}^{+}\end{array}$ & $K_{\mathrm{a} 1}^{\mathrm{int}}=\frac{[\mathrm{SOH}]\left[\mathrm{H}^{+}\right]}{\left[\mathrm{SOH}_{2}^{+}\right]} \exp \left(\frac{-\psi_{0} F}{R T}\right)$ \\
$\mathrm{SOH}=\mathrm{SO}^{-}+\mathrm{H}^{+}$ & $K_{\mathrm{a} 2}^{\mathrm{int}}=\frac{\left[\mathrm{SO}^{-}\right]\left[\mathrm{H}^{+}\right]}{[\mathrm{SOH}]} \exp \left(\frac{-\psi_{0} F}{R T}\right)$ \\
$\mathrm{SOH}+\mathrm{Na}^{+}$ & $K_{\mathrm{Na}+}^{\mathrm{int}}$ \\
$=\mathrm{SO}{ }^{-}-\mathrm{Na}^{+}+\mathrm{H}^{+}$ & $=\frac{\left[\mathrm{SO}^{-}-\mathrm{Na}^{+}\right]\left[\mathrm{H}^{+}\right]}{\left.\left[\mathrm{SOH}_{[}\right] \mathrm{Na}^{+}\right]} \exp \left[\frac{\left(\psi_{\beta}-\psi_{0}\right) F}{R T}\right]$ \\
$\begin{array}{l}\mathrm{SOH}+\mathrm{H}^{+}+\mathrm{NO}_{3}^{-} \\
=\mathrm{SOH}_{2}^{+}-\mathrm{NO}_{3}^{-}\end{array}$ & $K_{\mathrm{NO}_{\overline{3}}^{\mathrm{int}}}$ \\
$=\frac{\left[\mathrm{SO}_{2}^{+}-\mathrm{NO}_{3}^{-}\right]}{\left.\left[\mathrm{SOH}_{[}\right] \mathrm{H}^{+}\right]\left[\mathrm{NO}_{3}^{-}\right]} \exp \left[\frac{\left(\psi_{0}-\psi_{\beta}\right) F}{R T}\right]$
\end{tabular}

Outer-sphere complex

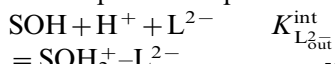

$=\mathrm{SOH}_{2}^{+}-\mathrm{L}^{2-}$

$$
=\frac{\left[\mathrm{SOH}_{2}^{+-}-\mathrm{L}^{2-}\right]}{[\mathrm{SOH}]\left[\mathrm{H}^{+}\right]\left[\mathrm{L}^{2-}\right]} \exp \left[\frac{\left(\psi_{0}-2 \psi_{\beta}\right) F}{R T}\right]
$$

$\mathrm{SOH}+2 \mathrm{H}^{+}+\mathrm{L}^{2-}$
$=\mathrm{SOH}_{2}^{+}-\mathrm{HL}^{-}$

$$
\begin{aligned}
& K_{\mathrm{HL}_{\text {out }}^{\text {int }}}^{\text {. }}=\frac{\left[\mathrm{SOH}_{2}^{+}-\mathrm{HL}^{-}\right]}{[\mathrm{SOH}]\left[\mathrm{H}^{+}\right]\left[\mathrm{L}^{2-}\right]} \exp \left[\frac{\left(\psi_{0}-\psi_{\beta}\right) F}{R T}\right]
\end{aligned}
$$

Inner-sphere complex

$\begin{aligned} & \mathrm{SOH}+\mathrm{H}^{+}+\mathrm{L}^{2-} \\ & =\mathrm{SL}^{-}+\mathrm{H}_{2} \mathrm{O}\end{aligned} \quad K_{\mathrm{L}_{\text {in }}}^{\mathrm{int}}=\frac{\left[\mathrm{SL}^{-}\right]}{[\mathrm{SOH}]\left[\mathrm{H}^{+}\right]\left[\mathrm{L}^{2-}\right]} \exp \left[\frac{-\psi_{0} F}{R T}\right]$

$\begin{aligned} & \mathrm{SOH}+2 \mathrm{H}^{+}+\mathrm{L}^{2-} \\ & =\mathrm{SHL}+\mathrm{H}_{2} \mathrm{O}\end{aligned} \quad K_{\mathrm{HL}_{\text {in }}}^{\text {int }}=\frac{[\mathrm{SHL}]}{[\mathrm{SOH}]\left[\mathrm{H}^{+}\right]\left[\mathrm{L}^{2-}\right]}$

\footnotetext{
${ }^{\text {a }} \mathrm{L}$ denotes $\mathrm{MoO}_{4}^{2-}, \mathrm{CrO}_{4}^{2-}, \mathrm{SO}_{4}^{2-}, \mathrm{SeO}_{4}^{2-}$ or $\mathrm{SeO}_{3}^{2-}$.
}

$\mathrm{SOH}_{n+1} \mathrm{~L}^{(n-2)}$ is the total surface species, $\mathrm{L}^{2-}$ is the total solution species, and $n$ is the overall proton coefficient. The overall proton coefficient includes the effects of all surface and solution reactions involved in anion adsorption. The larger value of $\mathrm{n}$ implies a higher affinity for anion adsorbed onto oxide surface. Additionally, the proton coefficient is influenced by the nature of the adsorbent and by the sorbate-to-surface site concentration ratio. The distribution ratio $(D)$ defined by

$$
D=\frac{\sum \text { surface species }}{\sum \text { solution species }}
$$

can be rewritten using Eqs. (9) and (10) so that $\log D$ is given by

$\log D=-n \mathrm{pH}+\log K_{\mathrm{e}}+\log [\mathrm{SOH}]$

$\log D=-n \mathrm{pH}+K$

Assuming $K\left(\log K_{\mathrm{e}}+\log [\mathrm{SOH}]\right)$ is a constant, the overall proton coefficient $(n)$ can, thus, be obtained by plotting $\log D$ versus $\mathrm{pH}$.

\section{Results and discussion}

\subsection{Effects of $p H$ and background electrolyte}

The individual sorption envelopes of $5 \times 10^{-3}$ $\mathrm{M}$ anions $\left(\mathrm{MoO}_{4}^{2-}, \mathrm{CrO}_{4}^{2-}, \mathrm{SO}_{4}^{2-}, \mathrm{SeO}_{4}^{2-}\right.$, and $\mathrm{SeO}_{3}^{2-}$ ) onto $30 \mathrm{~g} / 1 \gamma-\mathrm{Al}_{2} \mathrm{O}_{3}$ in the presence of three different $\mathrm{NaNO}_{3}$ electrolyte concentrations $(0.01,0.05$, and $0.1 \mathrm{M})$ are presented in Fig. 1. For all anions studied in this work, the sorption density increased with system $\mathrm{pH}$ shifting from alkaline to acidic conditions. Sorption of chromate (Fig. 1(b)), sulfate (Fig. 1(c)), and selenate (Fig. 1(d)) are affected by the $\mathrm{NaNO}_{3}$ concentration, especially chromate in the low $\mathrm{pH}$ region. In contrast, sorption of molybdate and selenite does not show any noticeable differences with three $\mathrm{NaNO}_{3}$ concentrations. As reported by other investigators $[4,5]$, the sorption envelopes of sulfate and selenate are dependent on the background 

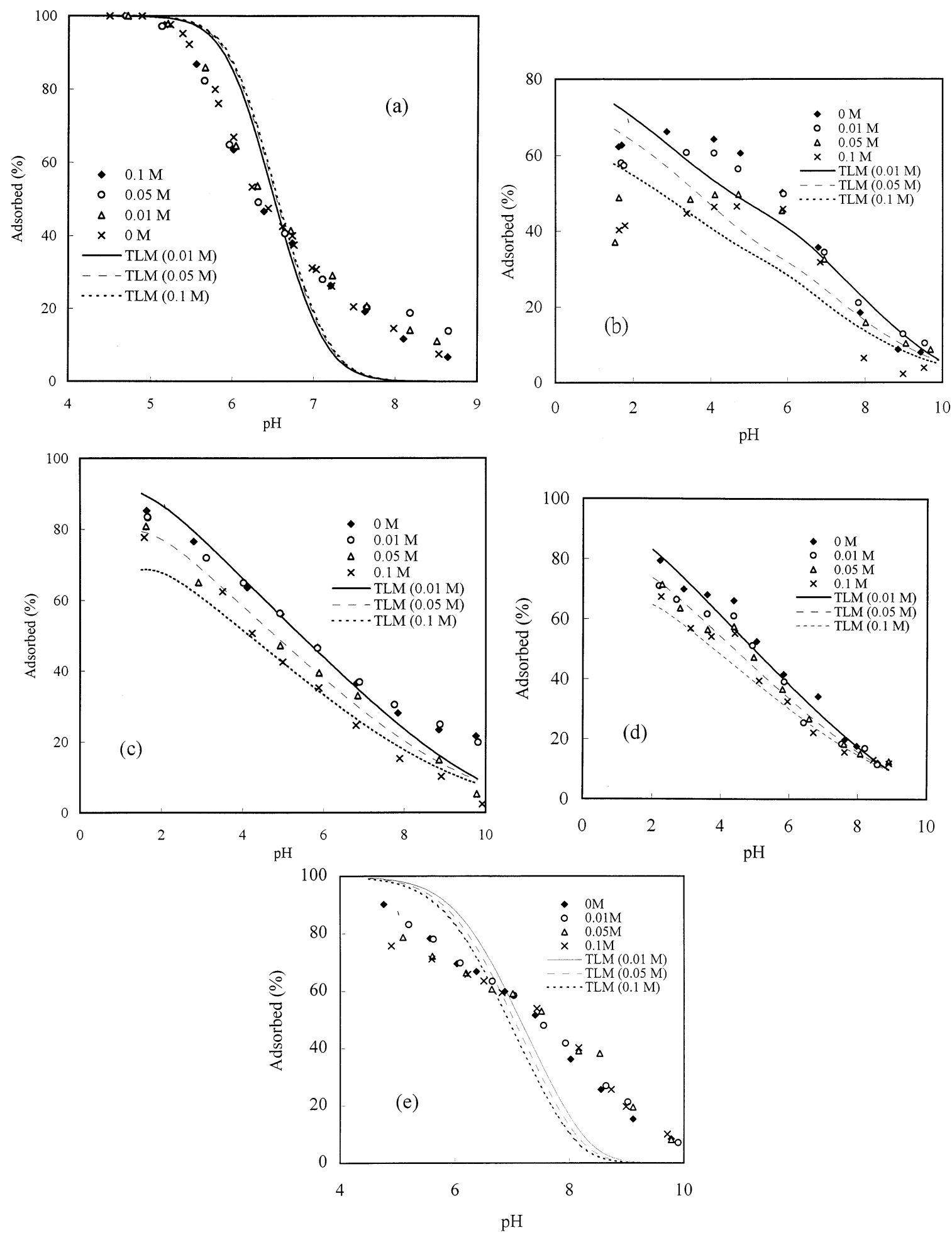

Fig. 1. Adsorption of anions onto $\gamma-\mathrm{Al}_{2} \mathrm{O}_{3}$ as a function of $\mathrm{pH}$ under various background $\mathrm{NaNO}_{3}$ concentrations. Symbols denote experiment data and line denotes the result of TLM simulation. (a) Simulation of $\mathrm{SMoO}_{4}^{-}$using Eq. (7). (b) Simulation of $\mathrm{SOH}_{2}^{+}-\mathrm{CrO}_{4}^{2-}+\mathrm{SOH}_{2}^{+}-\mathrm{HCrO}_{4}^{-}$using Eqs. (5) and (6). (c) Simulation of $\mathrm{SOH}_{2}^{+}-\mathrm{SO}_{4}^{2-}$ using Eq. (5). (d) Simulation of $\mathrm{SOH}_{2}^{+}-\mathrm{SeO}_{4}^{2-}$ using Eq. (5). (e) Simulation of $\mathrm{SSeO}_{3}^{-}+\mathrm{SHSeO}_{3}$ using Eqs. (7) and (8). 
electrolyte strength. The background electrolyte concentration influences the double layer thickness and interface potential, thereby affecting the binding of the adsorbing species. Outer-sphere complexes are expected to be more susceptible to ionic-strength variations than inner-sphere complexes, since the background electrolyte ions are placed in the same plane as the outer-sphere complexes. Consequently, sorption of $\mathrm{MoO}_{4}^{2-}$ and $\mathrm{SeO}_{3}^{2-}$ might imply the formation of innersphere complexes. On the other hand, $\mathrm{CrO}_{4}^{2-}$, $\mathrm{SO}_{4}^{2-}$, and $\mathrm{SeO}_{4}^{2-}$ are assumed to form the outersphere complexes because their sorption is strongly dependent on background electrolytes. The complex forms of the anion $/ \gamma-\mathrm{Al}_{2} \mathrm{O}_{3}$ system are verified by the following TLM simulation.

The maximum adsorption densities of $\mathrm{MoO}_{4}^{2-}$, $\mathrm{CrO}_{4}^{2-}, \mathrm{SO}_{4}^{2-}, \mathrm{SeO}_{4}^{2-}$, and $\mathrm{SeO}_{3}^{2-}$ calculated in this study are $1.67 \times 10^{-6}, 1.10 \times 10^{-6}, 1.42 \times$ $10^{-6}, 1.32 \times 10^{-6}$, and $1.50 \times 10^{-6} \mathrm{~mol} / \mathrm{m}^{2}$, respectively. For comparison, the adsorption densities of these anions on goethite surface are higher, or $4.06 \times 10^{-6}, 2 \times 10^{-6}, 2.46 \times 10^{-6}$, $1.59 \times 10^{-6}$, and $3.04 \times 10^{-6} \mathrm{~mol} / \mathrm{m}^{2}$, respectively $[4,5,8,9]$. The variances in the adsorption densities for each anion might be due to differences in laboratory conditions (e.g. adsorbate/adsorbent ratio) and adsorbate affinity for oxide surface.

During the course of a 24-h experiment as carried out by this study, $\gamma-\mathrm{Al}_{2} \mathrm{O}_{3}$ may dissolve and recrystallize. Therefore, this study also carried out additional experiments to verify the dissolution potential of $\gamma-\mathrm{Al}_{2} \mathrm{O}_{3}$ under controlled conditions in each adsorption systems. The results indicate that the dissolved $\mathrm{Al}^{3+}$ is significant only in the $\mathrm{CrO}_{4}^{2-} / \gamma-\mathrm{Al}_{2} \mathrm{O}_{3}$ system. The ratio of dissolved $\mathrm{Al}^{3+} /$ add $\mathrm{Al}^{3+}$ in $\mathrm{MoO}_{4}^{2-}, \mathrm{CrO}_{4}^{2-}, \mathrm{SO}_{4}^{2-}$, $\mathrm{SeO}_{4}^{2-}$, and $\mathrm{SeO}_{3}^{2-}$ systems is $0,3.2,0.15,0.12$, and $0 \%$, respectively. This result shows that the degree of dissolution of $\gamma-\mathrm{Al}_{2} \mathrm{O}_{3}$ induced by the adsorption of these anions is fairly insignificant. Stumm [25] illustrated that (complex-forming) ligands enhance the dissolution of $\mathrm{Al}_{2} \mathrm{O}_{3}$. Ligands such as oxalate, salicylate, $\mathrm{F}^{-}$, EDTA, and NTA accelerate dissolution, while others, $\mathrm{SO}_{4}^{2-}, \mathrm{CrO}_{4}^{2-}$ , and benzoate, tend to inhibit dissolution. Kraemer et al. [26] introduced $\delta-\mathrm{Al}_{2} \mathrm{O}_{3}$ dissolution in the presence of arsenate and the organic ligand HQS, finding that HQS promotes oxide dissolution and arsenate adsorbs to the $\delta-\mathrm{Al}_{2} \mathrm{O}_{3}$ surface but does not promote dissolution. Stumm et al. [27] showed that the most rapid dissolution rate is obtained when bidentate mononuclear surface chelates are formed and that monodentates are typically more inert with regard to dissolution reactions. Since the ligands in this study all form monodentate complexes and the focus of this study is not in dissolution, interactions between dissolution and adsorption were not performed.

\subsection{TLM simulation}

Species of $\mathrm{MoO}_{4}^{2-}, \mathrm{HCrO}_{4}^{-}, \mathrm{CrO}_{4}^{2-}, \mathrm{SO}_{4}^{2-}$, $\mathrm{SeO}_{4}^{2-}, \mathrm{HSeO}_{3}^{-}$, and $\mathrm{SeO}_{3}^{2-}$ are considered to react with $\gamma-\mathrm{Al}_{2} \mathrm{O}_{3}$ surface in the $\mathrm{pH}$ range evaluated according to the $\mathrm{pK}_{2} \mathrm{~s}$ listed in Table 2 . Molybdate and selenite are hypothesized to form an inner-sphere complex. Outer-sphere complex formation of $\mathrm{CrO}_{4}^{2-}, \mathrm{SO}_{4}^{2-}$, and $\mathrm{SeO}_{4}^{2-}$ was simulated by Eq. (5) in Table 3. The results of TLM simulation for the anions $/ \gamma-\mathrm{Al}_{2} \mathrm{O}_{3}$ systems are presented as the solid lines in Fig. 1. The fitness between the model prediction and experimental data indicates whether the assumption is acceptable or not. In this work, modeling sorption of molybdate, chromate, and selenite did not match the experimental data very well. The TLM was unable to coincide the molybdate sorption envelop data in the entire $\mathrm{pH}$ range probably because of the competition for reacting sites by $\mathrm{OH}^{-}$.

In the $\mathrm{CrO}_{4}^{2-} / \gamma-\mathrm{Al}_{2} \mathrm{O}_{3}$ system, the model in terms of the influence of ionic strength was unsatisfactory in the acidic pHs (Fig. 1(b)). $\mathrm{CrO}_{4}^{2-}$ and $\mathrm{HCrO}_{4}^{-}$are both treated to react simultaneously with the $\gamma-\mathrm{Al}_{2} \mathrm{O}_{3}$ surface under experimental conditions. Model simulation using Eqs. (5) and (6) in Table 3 suggests that $\mathrm{CrO}_{4}^{2-}$ and $\mathrm{HCrO}_{4}^{-}$form outer-sphere complexes. The configuration of chromate on oxide surface seems to be the most controversy issue in the past studies. Mikami et al. [1] have reported that chromate complex is in outer-sphere configuration, whereas Grossl et al. [8] conclude that chromate sorption on goethite is an inner-sphere bidentate surface complex, sug- 
gesting there may be a discrepancy in adsorption mechanism between an aluminum oxide and an iron oxide. The discrepancy on chromate surface complex can not be verified in this work; however, the results of the binary-solute experiments may infer that sorption of chromate onto $\gamma-\mathrm{Al}_{2} \mathrm{O}_{3}$ is more likely to form outer-sphere complexes.

The selenite system is similar to chromate with two species $\left(\mathrm{SeO}_{3}^{2-}+\mathrm{HSeO}_{3}^{-}\right)$reacting with the $\gamma-\mathrm{Al}_{2} \mathrm{O}_{3}$ surface under experimental conditions. The TLM simulation for selenite is presented in Fig. 1(e). This result shows there is some discrepancy between the TLM simulation and experimental data. Since the background electrolyte concentration influences the sorption of $\mathrm{SeO}_{3}^{2-}$ insignificantly, sorption of $\mathrm{SeO}_{3}^{2-}$ might imply the formation of an inner-sphere complex. Hayes [11] and Zhang and Sparks [5], however, suggest that both $\mathrm{HSeO}_{3}^{-}$and $\mathrm{SeO}_{3}^{2-}$ form inner-sphere complexes on goethite surface.

\subsection{Competitive adsorption}

Competitive adsorption was examined for anions of similar affinity to the $\gamma-\mathrm{Al}_{2} \mathrm{O}_{3}$ surface. As mentioned above, adsorption can be categorized either as inner-sphere or outer-sphere adsorption; therefore, competitive adsorption experiments are examined for these two parts. The experiment considered not only the affinity to the oxide surface but also the similar adsorption $\mathrm{pH}$ edges for each anion. The systems of $\mathrm{MoO}_{4}^{2-}+\mathrm{SeO}_{3}^{2-}$, $\mathrm{CrO}_{4}^{2-}+\mathrm{SO}_{4}^{2-}$, and $\mathrm{CrO}_{4}^{2-}+\mathrm{SeO}_{4}^{2-}$ were tested with results shown in Figs. 2-4, respectively. Competition between two anions for a given surface sorption site depends on the strength and type of the binding between the anion and the surface, and the binding rate on the surface.

In the binary-solute system of $\mathrm{MoO}_{4}^{2-}$ and $\mathrm{SeO}_{3}^{2-}$, the extent of anion sorption is both depressed by each other in comparison to the single solute system. The decrease in sorption of selenite was more severer than that of molybdate at $\mathrm{pH}<$ 7. Sorption of selenite was, however, unaffected in the presence of co-anion in alkaline pHs. In systems containing both strong adsorption anions, the competition seems to be dependent on the relative binding affinity of anions on oxide sur-

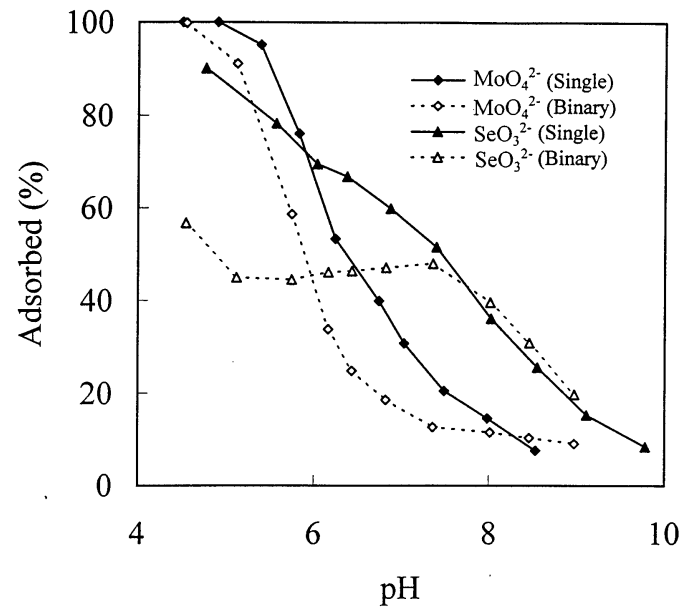

Fig. 2. Competitive adsorption of molybdate and selenite on $\gamma-\mathrm{Al}_{2} \mathrm{O}_{3}$ as a function of $\mathrm{pH}\left(\gamma-\mathrm{Al}_{2} \mathrm{O}_{3}=30 \mathrm{~g} / \mathrm{l},\left[\mathrm{MoO}_{4}^{2-}\right]=\right.$ $\left.\left[\mathrm{SeO}_{3}^{2-}\right]=5 \times 10^{-3} \mathrm{M}\right)$.

face. At $\mathrm{pH}<6$ where sorption of $\mathrm{MoO}_{4}^{2-}$ is preferred to that of $\mathrm{SeO}_{3}^{2-}, \mathrm{MoO}_{4}^{2-}$ sorption is able to out-compete $\mathrm{SeO}_{3}^{2-}$. In the contrast, at $\mathrm{pH}>6$ where sorption of selenite is stronger than molybdate, molybdate sorption is somewhat inhibited. The binary-anion systems of $\mathrm{CrO}_{4}^{2-} /$ $\mathrm{SO}_{4}^{2-}$ and $\mathrm{CrO}_{4}^{2-} / \mathrm{SeO}_{4}^{2-}$ exhibit similar results on competitive adsorption. Chromate adsorption is significantly restrained in the presence of sulfate or selenate in acidic pHs where a $40 \%$ decrease in

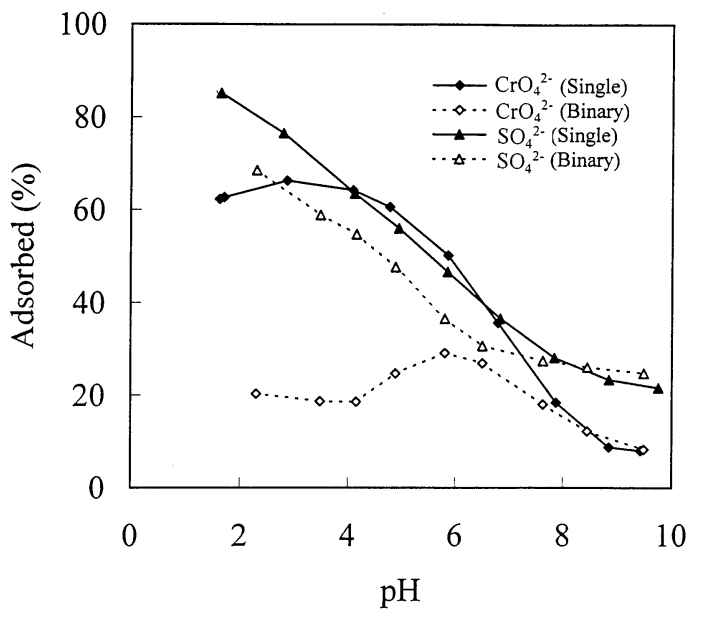

Fig. 3. Competitive adsorption of chromate and sulfate on $\gamma-\mathrm{Al}_{2} \mathrm{O}_{3}$ as a function of $\mathrm{pH}\left(\gamma-\mathrm{Al}_{2} \mathrm{O}_{3}=30 \mathrm{~g} / \mathrm{l},\left[\mathrm{CrO}_{4}^{2-}\right]=\right.$ $\left.\left[\mathrm{SO}_{4}^{2-}\right]=5 \times 10^{-3} \mathrm{M}\right)$. 


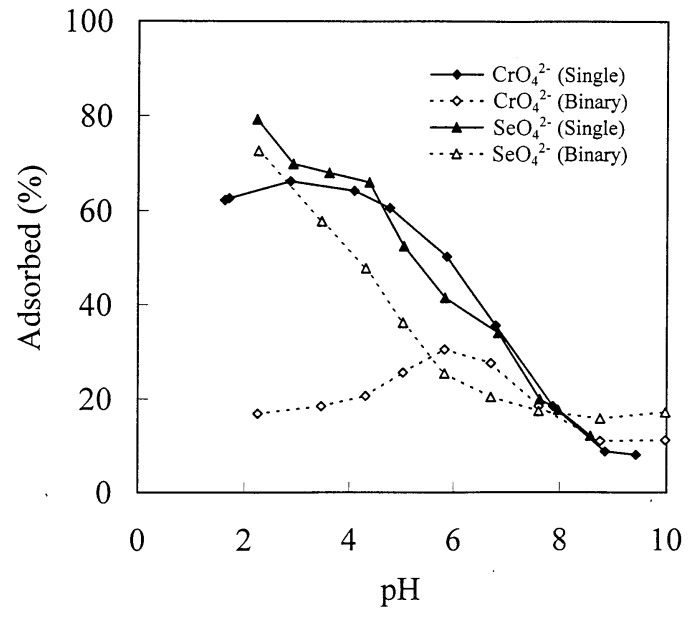

Fig. 4. Competitive adsorption of chromate and selenate on $\gamma-\mathrm{Al}_{2} \mathrm{O}_{3}$ as a function of $\mathrm{pH}\left(\gamma-\mathrm{Al}_{2} \mathrm{O}_{3}=30 \mathrm{~g} / \mathrm{l},\left[\mathrm{CrO}_{4}^{2-}\right]=\right.$ $\left.\left[\mathrm{SeO}_{4}^{2-}\right]=5 \times 10^{-3} \mathrm{M}\right)$.

chromate adsorption is noticed. If one were to consider the adsorption of chromate on oxide as an inner-sphere coordination, the out-competition by ion-pair sulfate or selenate sorption would be difficult to rationalize because of inner-sphere anion as a strong affinity adsorbate. By comparing the relative influence on competitive adsorption, it is suggested that sorption of chromate on oxide surface is more likely to form outer-sphere complexes.

The adsorption densities for single adsorbate and cosolutes are $1.67 \times 10^{-6}$ (single) and $1.66 \times$ $10^{-6} \mathrm{~mol} / \mathrm{m}^{2}\left(\mathrm{MoO}_{4}^{2-}+\mathrm{SeO}_{3}^{2-}\right)$ for $\mathrm{MoO}_{4}^{2-}$ and $1.50 \times 10^{-6}$ (single) and $9.46 \times 10^{-7} \mathrm{~mol} / \mathrm{m}^{2}$ $\left(\mathrm{MoO}_{4}^{2-}+\mathrm{SeO}_{3}^{2-}\right)$ for $\mathrm{SeO}_{3}^{2-}$. As shown in Fig. 3 , the sorption densities are $1.10 \times 10^{-6}$ (single) and $4.85 \times 10^{-7} \mathrm{~mol} / \mathrm{m}^{2}\left(\mathrm{CrO}_{4}^{2-}+\mathrm{SO}_{4}^{2-}\right)$ for $\mathrm{CrO}_{4}^{2-}$ and $1.42 \times 10^{-6}$ (single) and $1.14 \times 10^{-6}$ $\mathrm{mol} / \mathrm{m}^{2}\left(\mathrm{CrO}_{4}^{2-}+\mathrm{SO}_{4}^{2-}\right)$ for $\mathrm{SO}_{4}^{2-}$. In Fig. 4, the sorption densities for $\mathrm{SeO}_{4}^{2-}$ are $1.32 \times 10^{-6}$ (single) and $1.21 \times 10^{-6} \mathrm{~mol} / \mathrm{m}^{2}\left(\mathrm{CrO}_{4}^{2-}+\mathrm{SeO}_{4}^{2-}\right)$ and for $\mathrm{CrO}_{4}^{2-}$ are $1.10 \times 10^{-6}$ (single) and $5.09 \times 10^{-7} \mathrm{~mol} / \mathrm{m}^{2}\left(\mathrm{CrO}_{4}^{2-}+\mathrm{SeO}_{4}^{2-}\right)$. The results clearly indicate that $\mathrm{MoO}_{4}^{2-}$ inhibits $\mathrm{SeO}_{3}^{2-}$ adsorption and that $\mathrm{SO}_{4}^{2-}$ or $\mathrm{SeO}_{4}^{2-}$ depresses $\mathrm{CrO}_{4}^{2-}$. Zachara et al. [2] have indicated that inorganic $\mathrm{SO}_{4}^{2-}$ as well as $\mathrm{CO}_{2(\mathrm{~g})}$ and $\mathrm{H}_{4} \mathrm{SiO}_{4}$ distinctly reduces chromate adsorption and enhances the mobility of chromate. In this regard,
$\mathrm{CrO}_{4}^{2-}$ retention in the subsurface environment is suppressed in the presence of most anionic constituents in groundwater. This is similar to the results of this study for $\mathrm{CrO}_{4}^{2-}+\mathrm{SO}_{4}^{2-}$ and $\mathrm{CrO}_{4}^{2-}+\mathrm{SeO}_{4}^{2-}$ systems. From these experiments, the affinity or binding strength of $\mathrm{MoO}_{4}^{2-}$ is stronger than $\mathrm{SeO}_{3}^{2-}$ and that $\mathrm{SO}_{4}^{2-}$ or $\mathrm{SeO}_{4}^{2-}$ is stronger than $\mathrm{CrO}_{4}^{2-}$ at $\mathrm{pH}<6$.

The overall proton coefficients $(n)$ are calculated from the slope of Kurbatov plots. The plots of $\log D$ versus $\mathrm{pH}$ for anion $/ \gamma-\mathrm{Al}_{2} \mathrm{O}_{3}$ systems are displayed in Fig. 5. The results showed that the steepest and flattest slopes are $\mathrm{MoO}_{4}^{2-}$ and $\mathrm{SO}_{4}^{2-}$ $/ \mathrm{CrO}_{4}^{2-}$, respectively. The slopes for $\mathrm{MoO}_{4}^{2-}$, $\mathrm{CrO}_{4}^{2-}, \mathrm{SO}_{4}^{2-}, \mathrm{SeO}_{4}^{2-}$, and $\mathrm{SeO}_{3}^{2-}$ are $0.68,0.17$, $0.17,0.22$, and 0.38 , respectively. The order of overall proton coefficients given by the plots is $\mathrm{MoO}_{4}^{2-}>\mathrm{SeO}_{3}^{2-}>\mathrm{SeO}_{4}^{2-}>\mathrm{CrO}_{4}^{2-} \sim \mathrm{SO}_{4}^{2-}$

(Table 4). By comparing the overall proton coefficients and the results of the competitive adsorption experiments, it is suggested that a larger value of the overall proton coefficient corresponds to a higher affinity for the oxide surface.

\section{Conclusions}

Competitive adsorption of anions affects the partitioning and transport of anionic solutes in the subsurface and surface waters. Competition

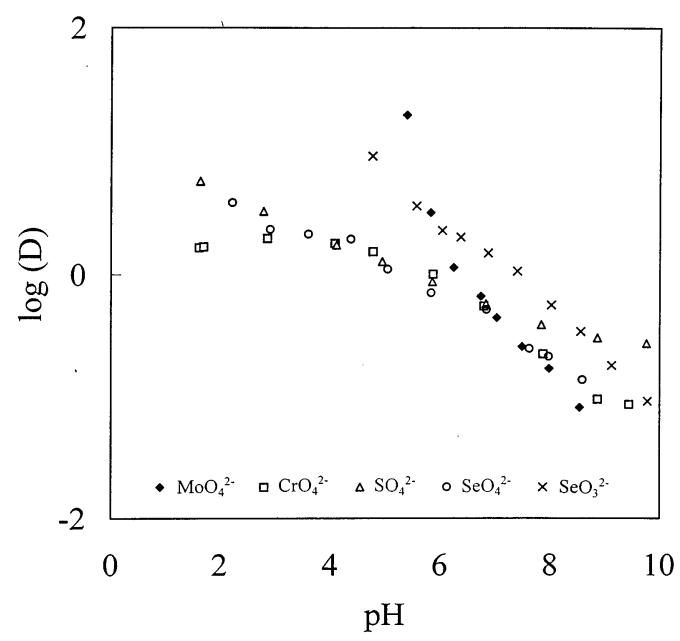

Fig. 5. Kurbatov plots for anion $/ \gamma-\mathrm{Al}_{2} \mathrm{O}_{3}$ systems. 
Table 4

Surface complexation reactions, equilibrium constants, and overall proton coefficients for anion $/ \gamma-\mathrm{Al}_{2} \mathrm{O}_{3}$ systems ${ }^{\mathrm{a}}$

\begin{tabular}{|c|c|c|}
\hline Anions & Reactions in system & $\log K_{\mathrm{eq}}^{\mathrm{int}}$ \\
\hline $\mathrm{MoO}_{4}^{2-}(0.68)$ & $\begin{array}{l}\mathrm{SOH}+\mathrm{H}^{+}+\mathrm{MoO}_{4}^{2-} \\
=\mathrm{SMoO}_{4}^{-}+\mathrm{H}_{2} \mathrm{O}\end{array}$ & 6.5 \\
\hline \multirow[t]{2}{*}{$\mathrm{CrO}_{4}^{2-}(0.17)$} & $\begin{array}{l}\mathrm{SOH}+\mathrm{H}^{+}+\mathrm{CrO}_{4}^{2-} \\
=\mathrm{SOH}_{2}^{+}-\mathrm{CrO}_{4}^{2-}\end{array}$ & 10.5 \\
\hline & $\begin{array}{l}\mathrm{SOH}+2 \mathrm{H}^{+}+\mathrm{CrO}_{4}^{2-} \\
=\mathrm{SOH}_{2}^{+}-\mathrm{HCrO}_{4}^{-}\end{array}$ & 14.5 \\
\hline $\mathrm{SO}_{4}^{2-}(0.17)$ & $\begin{array}{l}\mathrm{SOH}+\mathrm{H}^{+}+\mathrm{SO}_{4}^{2-} \\
=\mathrm{SOH}_{2}^{+}-\mathrm{SO}_{4}^{2-}\end{array}$ & 10.4 \\
\hline $\mathrm{SeO}_{4}^{2-}(0.22)$ & $\begin{array}{l}\mathrm{SOH}+\mathrm{H}^{+}+\mathrm{SeO}_{4}^{2-} \\
=\mathrm{SOH}_{2}^{+}-\mathrm{SeO}_{4}^{2-}\end{array}$ & 9.8 \\
\hline $\mathrm{SeO}_{3}^{2-}(0.38)$ & $\begin{array}{l}\mathrm{SOH}+\mathrm{H}^{+}+\mathrm{SeO}_{3}^{2-} \\
=\mathrm{SSeO}_{3}^{-}+\mathrm{H}_{2} \mathrm{O} \\
\mathrm{SOH}+2 \mathrm{H}^{+}+\mathrm{SeO}_{3}^{2-} \\
=\mathrm{SHSeO}_{3}+\mathrm{H}_{2} \mathrm{O}\end{array}$ & 5 \\
\hline
\end{tabular}

${ }^{a}$ The number in parentheses is the overall proton coefficient and $K_{\mathrm{eq}}^{\mathrm{int}}$ is the intrinsic equilibrium constant.

between anions with strongly binding affinity to form inner-sphere complexes is largely dependent on the relative sorption capabilities in the specific conditions. Molybdate and selenite are both strongly binding adsorbates. At comparable solute concentration, molybdate depresses selenite sorption at acidic environment and selenite suppresses molybdate sorption at alkaline conditions. For intermediately binding anions as chromate, selenate, and sulfate, adsorption of chromate is significantly inhibited in the presence of sulfate or selenate. The relative retainment of anions on oxide surface is molybdate $>$ selenite $>$ selenate $\sim$ sulfate $>$ chromate.

\section{Acknowledgements}

The authors thank Professor Olive J. Hao, University of Maryland, for the valuable discussions and the reviewers for their constructive comments. This work is partially funded by the $\mathrm{Na}$ tional Science Council of the Republic of China under Grant No. NSC 83-0410-E-002-082.

\section{References}

[1] N. Mikami, M. Sasaki, T. Klkuchi, T. Yasunaga, J. Phys. Chem. 87 (1993) 5245.

[2] J.M. Zachara, D.C. Girvin, R.L. Schmidt, C.T. Resch, Environ. Sci. Technol. 21 (1987) 589.

[3] C.C. Ainsworth, D.C. Girvin, J.M. Zachara, S.C. Smith, Soil Sci. Soc. Am. J. 53 (1989) 411.

[4] P.C. Zhang, D.L. Sparks, Soil Sci. Soc. Am. J. 54 (1990) 1266.

[5] P.C. Zhang, D.L. Sparks, Environ. Sci. Technol. 24 (1990) 1848.

[6] K. Mesuere, W. Fish, Environ. Sci. Technol. 26 (1992) 2365.

[7] J.A. Wilkie, J.G. Hering, Colloids Surf. A 107 (1996) 97.

[8] P.R. Grossl, M. Eick, D.L. Sparks, S. Goldberg, C.C. Ainsworth, Environ. Sci. Technol. 31 (1997) 321.

[9] P.C. Zhang, D.L. Sparks, Soil Sci. Soc. Am. J. 53 (1989) 1028.

[10] L.M. He, L.W. Zelazny, V.C. Baligar, K.D. Ritchey, D.C. Martens, Soil Sci. Soc. Am. J. 61 (1997) 784.

[11] K.F. Hayes, Equilibrium, Spectroscopic, and Kinetic Studies of Ion Adsorption at the Oxide/Aqueous Interface, Ph.D. Dissertation, Stanford University, Stanford, CA, 1987.

[12] S. Fendorf, M.J. Eick, P. Grossl, D.L. Sparks, Environ. Sci. Technol. 31 (1997) 315.

[13] W.R. Roy, J.J. Hassett, R.A. Griffin, Soil Sci. Soc. Am. J. 50 (1986) 1176.

[14] D. Hawke, P.D. Carpenter, K.A. Hunter, Environ. Sci. Technol. 23 (1989) 187.

[15] N.S. Bolan, J.K. Syers, M.E. Sumner, Soil Sci. Soc. Am. J. 57 (1993) 691.

[16] J.J. Dynes, P.M. Huang, Soil Sci. Soc. Am. J. 61 (1997) 772.

[17] L. Chatelet, J.Y. Bottero, J. Yvon, A. Bouchelaghem, Colloids Surf. A 111 (1996) 167.

[18] J.A. Davis, J.O. Leckie, J. Colloid Interface Sci. 67 (1978) 90.

[19] K.F. Hayes, J.O. Leckie, J. Colloid Interface Sci. 115 (1987) 564.

[20] J.B. Peri, J. Phys. Chem. 69 (1965) 211.

[21] K.F. Hayes, G. Redden, W. Ela, J.O. Leckie, J. Colloid Interface Sci. 142 (1991) 448.

[22] J.A. Davis, R.O. James, J.O. Leckie, J. Colloid Interface Sci. 63 (1978) 480.

[23] M. Hohl, W. Stumm, J. Colloid Interface Sci. 55 (1976) 281.

[24] D.D. Perrin, Ionisation Constants of Inorganic Acids and Bases in Aqueous Solution, Pergaman Press, New York, 1982.

[25] W. Stumm, Chemistry of the Solid-Water Interface, Wiley, New York, 1992.

[26] S.M. Kraemer, V.Q. Chiu, J.G. Hering, Environ. Sci. Technol. 32 (1998) 2876.

[27] W. Stumm, G. Furrer, E. Wieland, B. Zinder, in: J.I. Drever (Ed.), The Chemistry of Weathering, Reidel, Dordrecht, The Netherlands, 1985 , p. 55. 